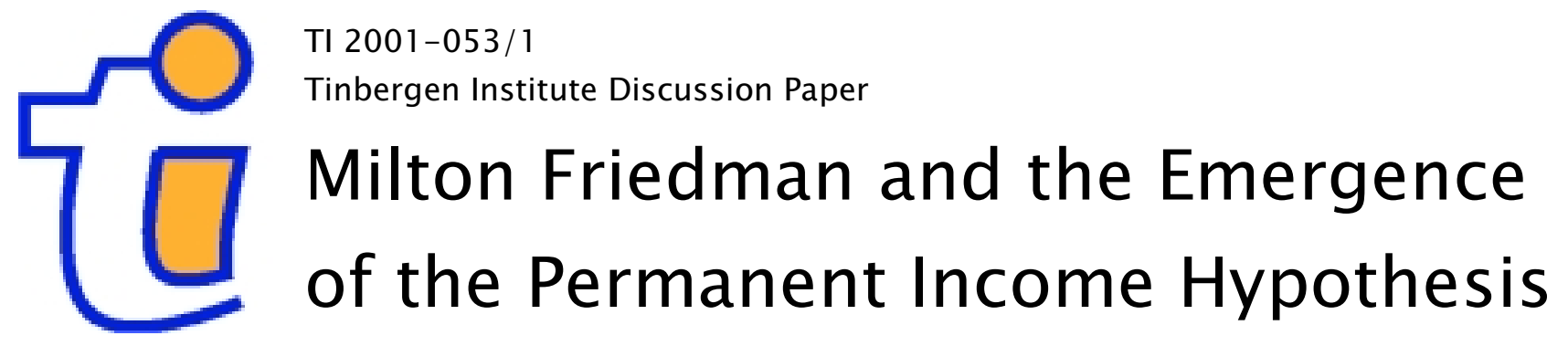

Hsiang-Ke Chao

Department of General Economics, Faculty of Economics and Econometrics, University of Amsterdam, and Tinbergen Institute 
Tinbergen Institute

The Tinbergen Institute is the institute for economic research of the Erasmus Universiteit Rotterdam, Universiteit van Amsterdam and

Vrije Universiteit Amsterdam.

Tinbergen I nstitute Amsterdam

Keizersgracht 482

1017 EG Amsterdam

The Netherlands

Tel.: +31.(0)20.5513500

Fax: $\quad+31 .(0) 20.5513555$

Tinbergen Institute Rotterdam

Burg. Oudlaan 50

3062 PA Rotterdam

The Netherlands

Tel.: $\quad+31 .(0) 10.4088900$

Fax: $\quad+31 .(0) 10.4089031$

Most TI discussion papers can be downloaded at

http://www.tinbergen.nl 


\title{
MILTON FRIEDMAN AND THE EMERGENCE OF THE PERMANENT INCOME HYPOTHESIS
}

\author{
Hsiang-Ke Chao \\ University of Amsterdam
}

November 2000

\begin{abstract}
The purpose of this paper is to investigate the evolution of Milton Friedman's permanent income hypothesis from the 1940s to 1960s, and how it became the paradigm of modern consumption theory. Modelling unobservables, such as permanent income and permanent consumption, is a long-standing issue in economics and econometrics. While the conventional approach has been to set an empirical model to make "permanent income" measurable, the historical change in the meaning of that theoretical construct is also of methodological interest. This paper will show that the concepts of unobservables, especially permanent income, in Friedman's work was fluid and depended on the instruments used.
\end{abstract}

\footnotetext{
This paper was prepared for the European Conferences on the History of Economics at Erasmus Institute for Philosophy and Economics, Erasmus University Rotterdam, the Netherlands, on 20-22 April 2000. I would like to thank Mark Blaug, Marcel Boumans, Jim Thomas, Kevin Hoover, members of the LSE-Amsterdam measurement group and the participants of ECHE 2000 for their comments. I particularly thank Mary Morgan for her comments and encouragement. All errors are mine.
} 


\section{INTRODUCTION}

In the early stage of his professional career, Milton Friedman worked on consumption theory, exploring the possible explanations of the relationship between consumption and income, for two decades. The well-known "permanent income hypothesis", often connected with his seminal book A Theory of the Consumption Function (1957), highlights Friedman's achievement in this field. Nonetheless, the permanent income hypothesis also raises the issue of defining and measuring "permanent income", which unavoidably correlates with performing the same tasks on "income". The modern definition of income is owed to Hicks's book Value and Capital (1939; 1946 2nd edn.) that identified income as the budget constraint of consumption behavior. But Hicks needed more specific definitions for empirical purposes. He claimed in his book that there are still great discrepancies between the theoretical definition and the empirical one and that existing theories couldn't help us with these discrepancies, i.e. the measurement problem. Thus he concluded that these income theories are "bad tools, which break in our hands" (1946, p.177).

While Hicks attempted to find a satisfactory empirical counterpart for a theoretically sound definition of income, other economists were conducting empirical studies of income structure. Among them, Kuznets was the most notable one. Apart from a series of works in the 1930s and 1940s on the measurement of national income, Kuznets started a study comparing incomes of different professions in 1933 by using data for 1929-32. He completed a draft in 1936 but

Friedman took up the work in 1937 and provided a more detailed statistical analysis ${ }^{\text {. The result }}$

\footnotetext{
${ }^{1}$ See Friedman and Kuznets (1945), pp. xi-xii.
} 
was published in 1945 entitled Income from Independent Professional Practice, by which Friedman earned his doctoral degree at Columbia University in 1946.

Income from Independent Professional Practice gives an account of income structure: income is composed of permanent, quasi-permanent and transitory components. It also marks the first of three stages of Friedman's research on the permanent income hypothesis. Each stage corresponds to a different concept of permanent income. In the second stage, identified by $A$ Theory of Consumption Function, Friedman continued to work on the dichotomy of measured income but extended it to the account of consumer behavior, i.e., the permanent income hypothesis. A formal statement of the permanent income hypothesis was given, several empirical models were built and tests for various types of data were proposed. Consequently this book is regarded as 'one of the masterpieces of modern econometrics' (Blaug, 1998, p.69). Finally, Friedman (1963) extended the treatment in Friedman (1957, Chapter V) that adopted Cagan's adaptive expectations hypothesis (Cagan, 1956) to the case of time-series data. By doing so the permanent income is equivalent to the adaptive expected income. It became the most popular version of permanent income.

Several surveys have explored the permanent income hypothesis extensively, namely, Mayer (1972), Hirsch and De Marchi (1990) and Hynes (1998). Mayer's book is the most well-known among them. Mayer indicates three definitions of permanent income in Friedman's work:

M1 Permanent income is whatever the household thinks it is.

M2 Permanent income is equal to the household's wealth times the relevant discount rate M3 Permanent income is an exponentially weighted average of past incomes plus a trend. 
Nonetheless, the main task of Mayer's book is to scrutinize the existing tests with respect to various data in order to appraise the permanent income hypothesis. But the interplay between data, models and theoretical definitions that appears in the permanent income hypothesis received less attention.

Both Hirsch and De Marchi (1990) and Hynes (1998) see Friedman's permanent income hypothesis as attempting to give a more empirically adequate account of consumption behavior, in the sense that the permanent income model is made "operational" by containing certain auxiliary statistical restrictions such that the permanent income hypothesis is capable of being subject to diagnostic testing. Hynes makes a stronger claim: namely that this modelling process goes in tandem with operationalism, which implies that the modelling procedure dictates the definition of the theoretical construct. Yet, such a claim does not completely fit Friedman's widely known methodological instrumentalist position. Such claims of operationalism need to be further justified.

This paper will illustrate the changing concept of the permanent income and the corresponding stages in Friedman's work on the permanent income hypothesis from the 1940s to 60s. Moreover, it also deals with the relations between the theoretical concepts, modelling procedures and different empirical evaluation methods and problems there encountered. Two empirical problems will be addressed: measurement and testing. Hicks regards models that improve the measurability of economic entities as good tools, but Friedman is more concerned with testing models. The conventional view on testing in economics is that tests always confirm or disconfirm the target theory or model. Friedman's case on the permanent income hypothesis can be said to present an alternative idea of testing, namely the "characteristics tests", meaning that only certain features of models are subject to test (Kim et al, 1995). Whether models are 
instruments for measuring or testing the permanent income hypothesis, they interact with the meaning of permanent income in different ways.

\section{MODELLING INCOME STRUCTURE}

The aim of the analysis presented in Income from Independent Professional Practice was to explain income differences among professions. The authors argued that given the free market mechanism, people with similar ability would receive the same return. The observation of income differences might suggest also the importance of the difference in institutional factors such as professional training, the attractiveness and risks of the profession and the like (Friedman and Kuznets, 1945, pp. v-vii). They conjectured that income differences are a compensation for longer training -- to equalize differences-- in a free market economy 2 Thus, apart from the description of the income structure, the classification of income determinants is also needed to interpret income differences. Since Friedman and Kuznets thought that income differences are determined by human capacities and institutional factors which affect income in different time spans, the taxonomy of income provides means to categorize the determinants of income by the length of period that a factor influences income. The components are called permanent if they are common over the specific time period, that is, "personal attributes such as training, ability, personality", or attributes of men's practice, such as "location, type, organization" and the like (Friedman and Kuznets, 1945, p.325). That is, permanent components are those effects on

\footnotetext{
${ }^{2}$ The authors concluded that the income differences between occupations are not the equalizing type for there are obstacles, such as high training fee, to present people from freely choose their occupations. On the other hand, movement within a profession is unhindered so that the income inequalities of a profession equalize the difference reflecting differences in age, location and the like. (See Friedman and Kuznets, 1945, ch.3).
} 
income which are present in the whole period of investigation. Transitory components, on the other hand, are defined as the factors whose effects on income exist within the single time unit. The remaining factors are grouped under the category 'quasi-permanent components'. The authors wrote that:

The dichotomy between permanent and transitory components of a man's income... necessarily does violence to the facts. An accurate description of the factors determining a man's income must substitute a continuum for the dichotomy. This continuum is bounded at one extreme by "truly" permanent factors- those that affect a man's income throughout his career-and at the other by the "truly" transitory- those that affect his income only during a single time unit, where the time period is the shortest period during which it seems desirable to measure income. ... Between these extremes falls what may be called "quasi-permanent" factors, factors whose effects neither disappear at once nor last through out a man's career (Friedman and Kuznets, 1945, p.352).

In other words, these three components are distinguished by the period they cover. For example, if a survey of income covers a three-year span, then the permanent components are those whose affect on income lasts for three or more years; the transitory components are those whose affects on income occur within the time unit, e.g. one year. Quasi-permanent components then might be two-year component, or a three-year component finished on the second year, and so forth.

In distinction to the other permanent income accounts, quasi-permanent components take part without been adequately identified. Friedman suggested a description of the quasi-permanent components that can be stated as follow (Friedman and Kuznets, 1945, p.353): 


$$
\begin{aligned}
& \text { Quasi-permanent components }=\text { two-year components ending this year } \\
& + \text { three-year components ending this year } \\
& + \text { four-year components ending this year } \\
& + \text { etc. } \\
& + \text { two-year component ending next year } \\
& + \text { three-year components ending next year } \\
& + \text { four-year components ending next year } \\
& + \text { etc. } \\
& + \text { etc. }
\end{aligned}
$$

The quasi-permanent component contains some features of interest. Permanent and transitory components are both defined by their specific time span, while the quasi-permanent component is not. Thus, the quasi-permanent components stand for those remaining uncategorized components. Some of them may be poorly-identifiable, for example, we know for sure that a certain component is neither permanent nor transitory, but the period it covers is unknown. That is to say, the quasi-permanent component usually serves as a residual, or a collective term that represents those factors other than permanent and transitory components. In this sense it is the quasi-permanent component that contains the measurement error if an empirical survey is conducted in which permanent income and transitory income can be identified. Therefore, the theoretical structure of quasi-permanent income is not sufficient to model it empirically. Nor is it sufficient to provide a formal model. In order to represent the income structure formally, Friedman had to manipulate the quasi-permanent component again. Friedman's formal mathematical representation of income can be summarized as follow: 


$$
y_{i}=p_{i}+t_{i}+\sum_{j=i}^{(i-1)+(n-1)} q_{i j}
$$

where $y$ is measured income, $p$ is permanent income, $t$ is transitory income and $q$ is transitory income. Subscript $i$ stands for the year in which income is received; $j$ is the year the quasipermanent component ends. Thus $q_{i j}$ represents the quasi-permanent income that the consumer units receives in the year $i$ but lasts till year $j$. Thus, according to equation (1), the quasipermanent component can only be expressed in the last year in which income is affected by the quasi-permanent components. In each year all the quasi-permanent components are categorized in $n$ - 1 catalogues in an $n$-period span. For example, in a three-period case, income is represented as:

$$
\begin{aligned}
& y_{1}=p_{1}+t_{1}+q_{11}+q_{12} \\
& y_{2}=p_{2}+t_{2}+q_{22}+q_{23} \\
& y_{3}=p_{3}+t_{3}+q_{33}+q_{34}
\end{aligned}
$$

Thus, it is not necessary to identify all the quasi-permanent components according to the general description above.

However, this formal representation is also not enough to proceed to the empirical survey. It can not be regarded as a satisfactory empirical model for it cannot solve that problem of how to distinguish, say, $q_{11}$ and the transitory component, $t_{l}$. Thus Friedman introduced more restrictions to estimate the influence of each component. Two approaches are employed to measure the contribution of each income determinant to the income variability: the mean assumption and the 
variability assumption. The mean assumption is that permanent and quasi-permanent components change in proportion to the change in the arithmetic mean income of the group, given that components are uncorrelated with one another-- which is called the zero correlation assumption. As the standard deviations of components can be derived, we can calculate the proportionate contribution of each of the three types of components to the total variance of income in any year. But the mean assumption approach is not sustainable. The problem lies in the inseparability of quasi-permanent income and transitory income for the reason mention above.

The variability assumption states that both the standard deviation of permanent and quasipermanent components are proportional to the standard deviation of measured income (but not to the standard deviation of transitory income). It also requires the assumption of zero correlation, but it has to be further assumed that the proportional contribution of the permanent component is the same in all years. Although under the variability assumption we can calculate the contribution of each component, Friedman did not think this assumption reasonable, for if permanent component and transitory component are uncorrelated and average permanent income is equal to average measured income, then it implies that the standard deviation of the permanent component is proportional to the standard deviation of the transitory component. Friedman argued that this is not reasonable for, by "theory", the transitory component should contribute a greater proportion to the variability of measured income than the permanent and quasi-permanent components. Therefore, the mean assumption is preferable.

The problem confronting Friedman is the measurement of vaguely defined theoretical constructs that do not translate the implicit causal account into a direct measurable structure. It is possible to measure the income components only indirectly by looking at the proportional 
contributions of income variance. Friedman's measurement of income in Income of Independent Professional Practice and the other early consumption studies are of methodological interest to economists. Hirsch and De Marchi (1990) and Hynes (1998) both address the importance of the operational meaning in the income structure model. Friedman's work is regarded as being in the tradition of the "operational development of income structure" (e.g., Hynes, 1998). But a theory that is operational does not necessarily imply operationalism, which is what Hynes suggests. To Hynes the term "operational" simply means a theory is model-able to the empirical level; that is, we can model a theory such that it fits the data (Hynes, 1998, pp.33-4). Defining an operationalist approach, however, requires that a theoretical term is defined by a set of operations, i.e. procedure of measurement. If we want to claim Friedman's approach at this stage consisted of operationalism, the only way to argue is that these income components depend on the measurement processes because a component is determined to be permanent or transitory by the length of time period in which it affects income. For instance, the transitory component is defined as a component that only affects income in the unit of time, which is decided mainly under the consideration of data availability. It also means that the transitory components may be defined by different units of time, so different concepts of transitory income are involved.

Claiming that the income structure is operational by employing the mean and variability assumptions does not mean we can directly measure these income components. At least no direct measurement of permanent and transitory income was conducted at this stage. In Income from Independent Professional Practice, the income of different professions is measured by questionnaires to professional men sent out by U.S. Department of Commerce (p.47). According to the questionnaires (Appendix C) income is defined as labor income (i.e., receipts from 
practice), implying that the concept of Hicksian income doesn't come into Friedman's first formation of permanent income.

\section{PERMANENT INCOME HYPOTHESIS-- BUDGET STIDIES}

Before Friedman addressed the permanent income hypothesis in A Theory of the Consumption Function (Friedman, 1957), several consumption theories were proposed to explain the stylized facts for which Keynes's absolute income hypothesis failed to give an account. This well-known

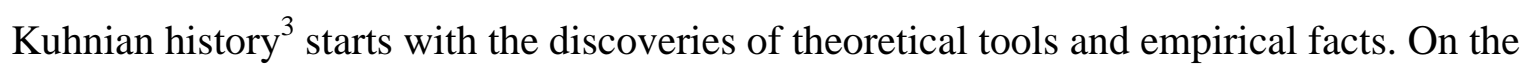
theoretical aspect, Friedman rediscovered the Fisherian intertemporal decision theory (Fisher, 1907) and emphasized his contention that the consumer smoothes his or her expenditures by borrowing and lending. Friedman claimed that the Fisherian approach to individual consumption behavior is the 'pure theory of consumption behavior' and that it makes the wealth approach a more sound account than Keynes's (Freidman, 1957, p.6). On the empirical aspect, Kuznets published a study of consumption and saving behavior in 1946 --one year after the publication of Income from Independent Professional Practice-- that indicated several empirical facts contradicting the predictions of the absolute income hypothesis. Keynesians argued that according to the absolute income hypothesis, the marginal propensity to consume (MPC) is less than the average propensity to consume (APC) and that MPC is less than one; thus (1) the average propensity to save (APS) increases as income rises; (2) APC decreases as income rise. (3) When government spending fell from the reached level during World War II, the economy would move toward recession, and then consumption would decrease. But Kuznets used time-

\footnotetext{
${ }^{3}$ Mayer (1972), Ch. 1, especially pp. 7-8; Hynes (1998).
} 
series data dating back to the Civil War to point out that (1) MPC is less than APC in budget data and short-run time-series data but is equal to APC in the long run; (2) APS and APC did not rise secularly and (3) private demand increased sharply and APS was sharply lower than in the interwar period level.

However, Friedman also defined permanent income in the sense of Hicksian income (Hicks, 1936/1945, Ch. XIV). Wealth is depreciated expected receipts (Friedman, 1957, pp.8-9); therefore income is defined as the amount that a consumer unit can consume while wealth remains unchanged (p.10). In Chapter II of A Theory of the Consumption Theory (p.17), permanent income is expressed as:

$$
y_{p}=i W
$$

where $i$ stands for interest rate, $W$ stands for wealth at a certain point of time. Wealth is depreciated income receipts; income --permanent income-- is defined as the amount that the consumer unit can consume but leave the wealth unchanged (Friedman, 1957, p.10). In Friedman (1963), $i$ is regarded as "an undefined term having the dimensions of an interest rate". Hicksian income is consistent with the Fisherian intertemporal decision theory in the sense that income is the present value of a stream of future receipts given the consumer unit's welfare position unchanged. It also refers to Mayer's definition two of the permanent income.

\subsection{The Formal Model}

In 'The Methodology of Positive Economics' (Friedman, 1953) Friedman claims that a theory contains two parts: a language and a body of substantive hypothesis. A language part 
functions as an 'analytical filing system' that categorizes components (Friedman, 1953, p.7). As an analytical filing system theory should meet both logical and empirical requirements. Friedman claims that on the logical aspect, the analytical filing system should (1) be clearly and precisely defined; (2) be exhaustive; (3) avoid cross-reference, and (4) be convenient to browse. On the empirical aspect, the filing system should provide an account to organize empirical material, thus we should be able to find for each category a 'meaningful empirical counterpart'. Formal logic shows whether the language part is 'right' or 'wrong' while the capacity of finding empirical counterparts shows whether the language is 'useful' or not (p.7).

Viewed as a model-building process, Friedman's account leads towards to an empirical model. The language part in his methodology is not only a verbal statement but also its formal representation, such as equation (1), that translates the theoretical claim of the income structure into a mathematical equation. Note that the language part is merely trivially true if it satisfies logically consistence; any consistent set of taxonomic criteria will do as well.

Nonetheless, the categorization cannot be claimed to be successful and useful if it fails to find empirical counterparts. If we may put it this way, Friedman's methodology of positive economics is concerned with translating verbal terms to theoretical terms and then to empirical terms.

The formal permanent income hypothesis can be stated as follows:

$$
\begin{aligned}
& c_{p}=k(i, w, u) y_{p} \\
& y=y_{p}+y_{t} \\
& c=c_{p}+c_{t} \\
& \operatorname{corr}\left(y_{t}, y_{p}\right)=\operatorname{corr}\left(c_{t}, c_{p}\right)=\operatorname{corr}\left(y_{t}, c_{t}\right)=0
\end{aligned}
$$


where $y$ stands for measured income; $c$ stands for measured consumption; $y_{p}$ is permanent income; $y_{t}$ is transitory income; $c_{p}$ is permanent consumption; $c_{t}$ is transitory consumption; $i$ is the interest rate; $w$ is the ratio of nonhuman wealth to permanent income and $u$ stands for factors such as age, family size etcetera that affect consumer's preferences ${ }^{1}$. Equations (3) to (5) represent the theoretical model of the permanent income hypothesis, stating the hypothetical relationships between measured constructs and theoretical constructs. Measured income is the sum of permanent income and transitory income. Similarly, measured consumption is the sum of its permanent and transitory components. Moreover, the model states the relationship between theoretical constructs: permanent consumption is a function of permanent income. Equation (3) asserts the proportional relation between permanent income and permanent consumption, which is regarded as the critical hypothesis of empirical content.

Zero-correlation assumptions (equation (6)) serve as an important part to make the whole model operational (e.g. Hirsch and De Marchi, 1990). It assumes that the correlation coefficients of these variables are zero. The first two correlations $\left(\operatorname{corr}\left(y_{t}, y_{p}\right)=\operatorname{corr}\left(c_{t}, c_{p}\right)=0\right)$ represent the nonstochasticity of the permanent component of income and the permanent component of consumption respectively. The nonstochasticity is based on the definition of transitory components and thus they 'have little substantive content'; then it can be explained as 'translating the definitions of theoretical constructs into formal representation' (Friedman, 1957, pp.26-7). The third correlation, $\operatorname{corr}\left(y_{t}, c_{t}\right)=0$, introduces important substantive content into the permanent income hypothesis. Bodkin (1960), for example, took this assumption as a 'crucial postulate' (p.176) because empirical findings do not always support this assumption. This

\footnotetext{
${ }^{4}$ Or as Holms (1970, p.1159) puts it, $u$ is "any objective factors affecting anticipations".
} 
assumption indicates that transitory income does not affect the consumer unit's planned consumption. However, Friedman argued that in fact consumers are able to use their windfall receipts on planned consumption, whereas windfall receipts are usually statistically recorded as transitory income. Friedman claimed that unexpected windfall receipts are regarded as transitory income while expected receipts are regarded as permanent income. It leads to the measurement problem that empirical notions employed in collecting statistical data are not consistent with the theoretical meanings posited by the theory and the model. Moreover, it calls the measurement of consumption into question, i.e., whether consumption should be defined in the 'use' sense or in the 'purchase' sense $\mathrm{e}^{\mathrm{E}}$. On this picture, there is much to say about the empirical content and the zero correlation between $y_{t}$ and $c_{t}$ as it shows the route of influence from theory to the procedure of measurement.

\subsection{Tests and the Characteristics Test}

While the conventional view on testing in economics is about rejecting candidate hypotheses, Kim et al (1995) assert other types of testing exists in economics and econometrics. There are confirmationalist tests that (1) secure a basis for belief or look for satisfactoriness of empirical models and (2) confirm the characteristics of empirical models ${ }^{6}$ With respect to secure belief, as Kim et al point out, economists would test to "seek in quantification a secure basis for consensual belief", such as using "econometrics as a measuring device to reassure the theorist in his or her belief (Kim et al, 1995, p.83)"'. It seems that tests in A Theory of the Consumption

\footnotetext{
${ }^{5}$ See Friedman (1957) and Mayer (1972), pp.12-16.

${ }^{6}$ In their article, four types of test are mentioned: (1) testing to discover error, (2) testing to secure a basis for belief (3) testing as quality control and (4) tests as confirmations of empirical model characteristics.
} 
Function behave as the former that are proposed to secure the belief that consumption is determined by permanent income. Friedman said that the consistency of the permanent income hypothesis with data supports the belief that the permanent income hypothesis is a useful tool to explain "the major apparent anomalies that arise if the observed regression between measured consumption and measured income is interpreted ... as a stable relation between permanent components" (Friedman, 1957, p.225).

Most economists are concerned with testing the permanent income hypothesis. Mayer's book documents the activities of testing the permanent income hypothesis from the 1950 s to the 70 s. Nonetheless, none of the tests confirm or disconfirm the entire permanent income hypothesis Even Friedman's tests are not able to do so:

Friedman presented a wide variety of tests, the results of which are consistent with his theory. But most of the tests are no more than this; they do not require a full permanent income theory to explain the observations. They are tests of the direction only, rather than rigorous tests of the full theory. By "tests of direction" I mean tests which show that two coefficients differ in the direction predicted by the permanent income theory, but not necessarily by the amount predicted by the theory (Mayer, 1972, pp.59-60).

The characteristics test refers to a type of tests that target on a specific property of the empirical model, the model that is derived from theory and is capable of processing quantitative information. In other words, a characteristics test is to match data characteristics with characteristics of the empirical model. But when we narrow the theory into the empirical model serving as a testable hypothesis, it does not guarantee the theory is justified. Kim et al point out

\footnotetext{
${ }^{7}$ See Mayer (1972), p.59.
} 
that (1) inference from data characteristics to empirical model characteristics are not unique.

Different empirical models may result in same data characteristics. (2) Inference from empirical models to theory is not possible for different theories can result in the same empirical models. As Gilbert (1986) criticized the conventional econometrics approach (average economic regression (AER) view), an OLS regression can be explained by different theories. Moreover, it is arguable whether the empirical model captures essential characteristics of the theory. In most of the cases when we try to produce an empirical model, we try to reduce the theory to a simple testable characteristic. By doing so the empirical model hardly represents the essences of theory.

Several implications derived from the model were thought to be the key properties of the permanent income hypothesis: (1) the proportional hypothesis, (2) difference in income elasticities between permanent and transitory components, (3) zero income elasticity of consumption for transitory income, (4) the lag hypothesis $\frac{8}{4}$ Mayer (1972, p.90) shows that none of the 16 tests that Friedman proposed in (1957) cover these four major predictions (i.e. characteristics) of the permanent income hypothesis. These tests are characteristics tests: they only confirm certain characteristics of empirical model ${ }^{6}$. These tests support the argument Kim et al made that the characteristics tests even fail to justify the essential characteristics of the theory. Mayer argued that "none of the tests support the full permanent income theory in the sense of

\footnotetext{
${ }^{8}$ See Mayer (1972) for detail.

${ }^{9}$ Friedman claims that "the two most striking pieces of evidence for the hypothesis are, first, its success in predicting in quantitative detail the effect of classifying consumer units by the change in their measured income from one year to another; and, second, its consistency with a body of data that have not heretofore been regarded as relevant to consumption behavior, namely, data on measured income of individual consumer units in successive years". However, it does not say that the evidences support the full model of the permanent income hypothesis. Horses cannot prove the existence of unicorns.
} 
showing that the income elasticity of consumption is zero for transitory income and unity for permanent income" $\left(1972\right.$, p.89) $\frac{10}{1}$.

\subsection{Windfall Experiment}

Having viewed $\operatorname{corr}\left(y_{t}, c_{t}\right)=0$ as a crucial assumption, Friedman suggested using National Service Life Insurance (NSLI) dividends that were paid out to US veterans in January 16, 1950 as windfall income to test it. The NSLI case seemed to be a "controlled experiment" of consumption behavior (Friedman, 1957, p.215) such that it was somehow regarded as a sort of crucial test of the permanent income hypothesis. Bodkin (1960) took over Friedman's suggestion and found that the MPC for NSLI dividends is 0.72 , even greater than the MPC for regular income (0.56). Although he had reservations about this result, Bodkin concluded that people do spend transitory income, thus the permanent income hypothesis was not sustainable. But Friedman (1960) responded that NSLI dividends was not a good measure of transitory income either, but rather would be a proxy of permanent income because recipients were told that additional payments would be forthcoming.

The debate raised the issue of the measurement problem, that is, how to find empirical counterparts according to the definitions chosen. Friedman argued that NSLI is not a good estimate of windfall income because part of it was expected. Interestingly, Bodkin thought NSLI dividend was a better proxy of the windfall than others used in the previous test on windfall payments proposed by Klein and Liviatan (1957). Klein and Liviatan's windfall proxy was not legitimate for some components of windfall income are not transitory. For instance, Bodkin

\footnotetext{
${ }^{10} \mathrm{It}$ is argued that the proportional hypothesis is another essential characteristic of the permanent income hypothesis (Mayer), but according to Mayer's survey, only 4 out of 16 tests check the proportional hypothesis.
} 
argued controversially that gambling wins for the professional gamblers are 'permanent income' (p.179).

The problem is twofold. Firstly, windfall income is often conflated with transitory income as windfall income is said to be a transitory element. Contrary to this popular belief, windfall income is not equivalent to the transitory income ${ }^{1}$. The relations between windfalls and permanent income and transitory income is based on equation (2) (i.e., $y_{p}=i w$ ). Windfall income raises wealth at the first place, such that it raises permanent income as well. The windfall income does not affect the transitory income directly because the transitory income is defined as the difference between measured income and permanent income. Friedman (1957) saw incomes as stocks, such that if the discount rate is one-third, one-third of the windfall is permanent income and two-thirds is transitory income. Friedman (1963) saw incomes as flows; the influence of windfall on the transitory income depends on (1) the point of time it is received and (2) the length of accounting period. Consequently, the windfall income is equal to the transitory income only in some special cases $\frac{12}{12}$.

Secondly, the problem results from the vagueness of the definitions. Friedman later claimed that 'the notion of 'windfall' is therefore logically identical with that of positive 'profit' in the uncertainty theory of profit" (1963, p.6, fn.3), meaning that windfall is unexpected income receipts. Hence gambling wins are windfall income but not transitory income. Bodkin's criticism

\footnotetext{
${ }^{11}$ Bodkin seemed to take windfall income and transitory income as synonyms, so did Mayer (1972). For example, Mayer (p.93) wrote that "[NSLI] was unexpected, and hence qualifies as a windfall, or transitory income". He took the consumption increased by windfall as the consumption out of permanent income, not the consumption of transitory income per se (1971, pp.39-40). But this account requires independent estimates of consumption from permanent income and from transitory income. Unfortunately, such estimates do not exist (Mayer, 1971, pp.40-41). ${ }^{12}$ See Friedman (1963) pp.15-16 for examples.
} 
of Klein and Liviatan might be misleading. Moreover, Friedman admitted that permanent and transitory incomes are arbitrary concepts: "The division [of permanent and transitory income] is, of course, in part arbitrary, and just where to draw the line may well depend on the particular application. Similarly, the dichotomy between permanent and transitory components is a highly special case (Friedman, 1957, p.22, fn.3). Similarly, Friedman defined the transitory income as a

residual (measured income minus permanent income) ${ }^{13}$ and 'its interpretation in empirical work depends on particular circumstances and the particular group of time units or consumer unit considered (Friedman, 1963, p.20).

\section{TIME-SERIES DATA STUDIES}

Several economists, such as Modigliani, Duessenberry and Mack $\frac{14}{4}$, undertook survey work on the relationship between consumption and current and past income in the traditions of the relative income hypothesis. However, Friedman (1957) thought that even though past income might be a means to estimate permanent components, claiming consumption depends on the ratio of income to the highest previous income is too arbitrary ${ }^{15}$. Instead he argued that a weighted average of past and current income seems to be a plausible estimate of permanent income. With respect to the time-series data, the estimate of permanent income, $y_{p}^{*}$, can be expressed as:

\footnotetext{
${ }^{13}$ Formal statements see Friedman (1963), pp.11-19.

${ }^{14}$ See Friedman (1957), Mayer (1972).

${ }^{15}$ See Friedman (1957, p.142).
} 


$$
y_{p}^{*}(T)=\int_{-\infty}^{T} w(t-T) y_{m}(t) d t
$$

where $y_{m}$ is the measured income; $w(t-T)$ is the weighting pattern such that:

$$
\int_{-\infty}^{T} w(t-T)=1
$$

Friedman used an exponential weighting pattern:

$$
w(t-T)=\beta e^{\beta(t-T)}
$$

where $\beta$ is the subjective discount rate. This form makes the weighting pattern equivalent to the form of the adaptive expectations that Philip Cagan used to estimate the expected rate of price

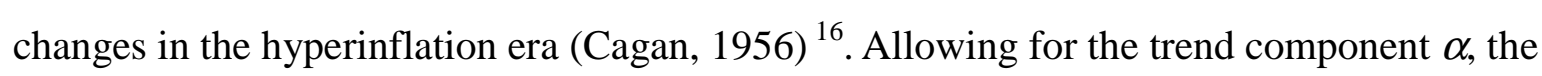
estimate of permanent income becomes $\frac{17}{17}$.

$$
y_{p}^{*}(T)=\beta \int_{-\infty}^{T} y_{m}(t) e^{(\beta-\alpha)(t-T)} d t
$$

\footnotetext{
${ }^{16}$ Also see Koyck (1954), Nerlove (1958a) and (1958b) for early essays on the form of adaptive expectations (i.e. the distributed-lag equation).

${ }^{17}$ That is, if $\alpha=0$, then equation (9) is the solution of the adaptive expected income that income adjustment depends on the past experience between expected income and realized income: $\frac{d y_{p}^{*}}{d T}=\beta\left[y_{m}(T)-y_{p}^{*}(T)\right]$.
} 
Friedman (1963) further interpreted permanent income in terms of adaptive expectations and argued that it is more satisfactory to apply this definition in the aggregate data. Friedman claimed that the adaptive expected income proxies the permanent income hypothesis "more closely and rigorously" than previous accounts and is more "aesthetically preferable" (Friedman, 1963, p.25).

Thus Friedman's three different concepts of permanent income are associated with his three major pieces of work:

F1 Permanent income is affected by the permanent components whose effects on income last more than a certain period of time (Friedman and Kuznets (1945)).

F2 Permanent income is the amount that a consumer unit can consume while wealth remains intact: $y_{p}=i W($ from Friedman (1957)).

F3 Permanent income is estimated by a weighted pattern of past income (Friedman (1957, 1963)).

Two of Mayer's three definitions (see Section 1) of permanent income loosely correspond to two of these three definitions: M2 is equal to F2 and M3 is equal to F3. But M1 is not equal to F1. In order to explain the stylized facts of the interwar period mentioned above, Friedman formulated the permanent income hypothesis. By maintaining the original notions of permanent and transitory components of income as the same ones in Income from Independent Professional Practice, Friedman proposed an income structure constructed by the components distinguished 
by their periods of affecting income. But he went further to specifically define the permanent component as 'the (consumer) unit regarded as determining its capital value of wealth' (1957, p.21). Thus Mayer concluded the first definition of the permanent income (M1): "permanent income is whatever the household thinks it is". Mayer's interpretation reflects the received view on permanent income as a subjectively expected income while the concept of the permanent income in Income from Independent Practical Profession opened the door for the objective measurement of permanent income.

Even though Mayer claimed that the concept of wealth does not play an important role in the permanent income hypothesis, defining and measuring wealth is still necessary because the permanent income is defined in terms of wealth (M2 and F2). By interpreting permanent income as expected income (M3), it seems merely a specific case of definition two. At first glance equation (9) is consistent with equation (2) conditioned on:

(1) there is no trend component $(\alpha=0)$ and

(2) the subjective discount rate $(\beta)$ equals to the interest rate $(i)$.

But the trend component can not ignored, for $\alpha$ estimates the known past rate of wealth increase. Friedman (1963) extended the account for time-series data in A Theory of the Consumption Function and argued that adaptive expectations state that the consumer unit learns from his or her past. Since the trend component reflects the difference between past income and current income, it should be taken into account when the consumer unit forms expectations on future income (Friedman, 1963, pp.22-23). 
Another key point is the interpretation of the "horizon", the length of time needed to demarcate permanent and transitory income. Permanent components are those whose effects on income last beyond the time period whereas transitory components are those whose effects are within this period. Despite that transitory income is now composed of the transitory and quasipermanent components as defined in his 1945 work, it seems consistent with that first version of his permanent income hypothesis. But there are still some puzzles. For instance, the horizon is defined as the inverse of $\beta$. According to Friedman's calculation, $\beta$ is about one-third, so the horizon is about three years. However, Friedman suggested strongly that the three-year horizon does not imply that permanent income is a three-year moving average of measured income because consumer units look over the horizon to form this expectations (Friedman, 1963). This casts doubt on how the moving average account matches the 1945 version of the permanent income hypothesis. For example, Holms (1970) admitted that by looking at the model, he doesn't see any reason why permanent income is not a three-year moving average of measured income.

\section{DISCUSSIONS}

In this section we further explore some issues related to the permanent income hypothesis that have been raised above. (1) How Friedman's permanent income model serves as a different instrument from Hicks's model, (2) The relation between a model's possibility to be operational to operationalism and instrumentalism and (3) the issue of measuring unobservables. 


\subsection{Hicks versus Friedman}

When discussing the early history of the permanent income hypothesis, Hynes (1998) argues that Hicks had already defined permanent income in Value and Capital (1936/1946). Hynes also notes that the idea of the permanent income hypothesis 'was in the air' in the 1940s. Indeed in Value and Capital Hicks defines income in relation to consumption behavior as a sort of expected income, a 'subjective concept, dependent on the particular expectations of the individual in question' (p.177):

the purpose of income calculation in practical affairs is to give people an indication of the amount which they can consume without impoverishing themselves. Following out this idea, it would seems that we ought to define a man's income as the maximum value which he can consume during a week, and still expect to be as well off at the end of the week as he was at the beginning. Thus, when a person saves, he plans to be better off in the future; when he lives beyond his income, he plans to be worse off. Remembering that the practical purpose of income is to serve as a guide for prudent conduct, I think it is fairly clear that this is what the central meaning must be (Hicks, 1946, p.172).

This passage also sheds some light on the concept of Hicksian demand, but the primary concern here is to measure the concept 'income'. Hicks further provided three definitions of income for the purpose of measurement, they are all defined in the fashion that income is the maximum amount which a consumer unit can spend during the current period of time and still

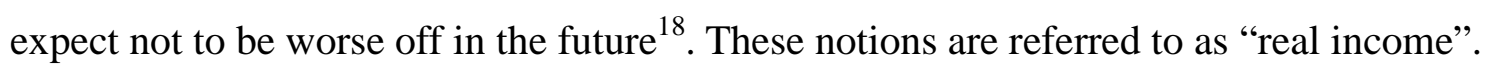

\footnotetext{
${ }^{18}$ The basic definition is "the maximum amount of money which consumer unit can spend in the present time and expect to be able to spend the same amount in the future" but under different assumptions. Definition one assumes
} 
However, these three definitions are purely theoretical, their usefulness is decided by measurability. That is, either definition can guide us to construct the empirical counterpart for each component of income, or the existing empirical data can be applied to fit the theoretical framework. Hicks's main task was to search for a measurable definition of his theoretical construct. The main problem was that measured income is not equal to expected income. Hicks applied the Stockholm school's concepts of ex ante and ex post to illustrate this problem. Because expectations are seldom realized, income ex ante is not equal to income ex post. Although it is not a novel idea, what makes Hicks's account an early permanent income hypothesis is his categorization of income into expected and unexpected components. Measured income (i.e., income ex post) is equal to expected income (i.e. income ex ante) plus windfall receipt (pp.177-9). But for Hicks these dynamic income hypotheses were 'bad tools' because these definitions are so 'complex' and 'unattractive' that they are not capable of finding empirical counterparts for income so defined.

Nonetheless, it is not sufficient just to claim that Hicks's account is a permanent income hypothesis. It is true that Hicks's account consists of permanent and transitory components of income. But instead of measuring consumption in terms of income, Hicks's intention was to measure income in terms of consumption. Moreover, the measurement problem confronting Hicks did not seem to bother Friedman. Friedman argued that empirical data can be adjusted to fit the definition of the theoretical construct in such a way that we can treat 'adjusted ex post magnitudes as if they were also the desired ex ante magnitudes (Friedman, 1957, p.20). But expected income does not necessarily imply permanent income. As we have seen, in Income

that interest rates and prices are constant. Definition two assumes interest rates change but prices don't. Definition three assumes both interest rate and prices change, so income is defined in real terms. See Hick (1946), p.172-4. 
from Independent Professional Practice (definition F1) the formation of expectations is irrelevant to permanent income. Definition F2 and F3 are in the category of expected income and Friedman's contribution was to add the proportional hypothesis in order to predict consumption behavior.

But in fact Friedman had to solve other measurement problems in order to save his permanent income hypothesis. Two empirical definitions have to be modified: First, consumption should be defined in terms of purchases such that spending on durable goods is included in the measurement of consumption 19 . Second, consumption is not derived from the subtraction of saving from income; consumption and income must be measured independently. If consumption is measured by subtracting saving from income ${ }^{20}$, then income and consumption would have

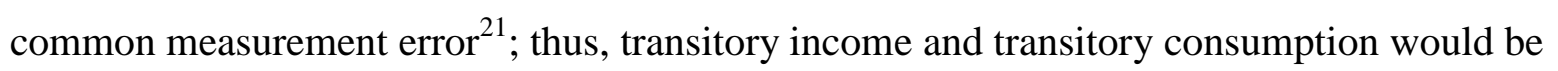
positively correlated. Thus the assumption $\operatorname{corr}\left(y_{t}, c_{t}\right)=0$ does not survive; neither does the permanent income hypothesis. In this sense, this zero-corrleation assumption introduces instrumentalism into the permanent income hypothesis. Friedman said that the zero-correlation assumption is not the only plausible one, but it is proposed for its usefulness in predicting consumer behavior (Friedman, 1957, p.29). This creates a taxonomy of consumption (i.e., deciding which factors are included in consumption measurement and which are not) on the empirical side, but it is determined by suggestions on the theoretical side.

\footnotetext{
${ }^{19}$ Darby (1972) argues that if transitory income is received in the form of nonhuman wealth, the purchases on durable goods would increase.

${ }^{20}$ As in Keynes (1936).

${ }^{21}$ On his comment on Liviatan (1963) (the same volume, pp.59-63), Friedman took this point as the main criticism.
} 


\subsection{Instrumentalism versus Operationalism}

Although the permanent income hypothesis intrinsically involves a problem of measurement of unobservables, Friedman put it in a different way: "the central idea [of the permanent income hypothesis] is to interpret empirical data as observable manifestations of theoretical constructs that are themselves regarded as not directly observable" (1957, p.23). This paragraph, representing the instrumentalist position, probably simplifies the problem of measuring unobservables in economics, in which the permanent income hypothesis has always been an outstanding exemplar. The role of economic models in instrumentalism is to match the features of phenomena, e.g., the proportionality hypothesis to predict stable-and-less-than-one APC. To put it differently, the model is justified if the APC confirms the proportional hypothesis. Thus, for instrumentalists, testing a model with empirical data seems to be the primary concern. Friedman said that the formal permanent income model is one of "converting the rather commonplace observation that consumer units adjust consumption to longer-term income prospects into an operationally meaningful theory capable of being contradicted by observation (Friedman, 1963, p.3)". Models should be operational in the sense that classical econometric assumptions are satisfied such that models can be subject to testing.

It is claimed in Hynes (1998) that one of the main methodological contributions of

Friedman's permanent income hypothesis as well as of other economists such as Margaret Reid and Simon Kuznets is that their researches addressed the formation of an operational theory of consumption. (Hynes, 1998, pp.33-5). Moreover, he interprets "operational" in terms of operationalism developed by of the philosophy of Bridgman (1936). Bridgman's operational philosophy only grants operational meanings to that which is given by a measuring process. As an experimentalist, Bridgman wished to base concepts on laboratory operations, or thought 
experiments suggested by laboratory practice. It suggests that the meaning of a theoretical construct is mainly determined by empirical operations (e.g., measurement procedures) and the interaction between objects and instruments (e.g. measuring devices). There is no unique definition for the objects, for example, if we use different tools and different measurement procedures to measure the length of the table, then each measure is regarded as a distinct definition of length. The tools that are not based on empirical observations, such as mathematics, result in meaningless outcomes:

[Mathematics] begins by being a most useful servant when dealing with phenomena of the ordinary scale of magnitude, but ends by dragging us by the scruff of the neck willy nilly into the inside of an electron where it forces us to repeat meaningless gibberish (Bridgman, 1928, p.149).

But establishing an "operationally meaningful theory" does not mean that Friedman accepted “operationalism”, even though both instrumentalism and operationalism are anti-realism. Operationalism defines unobservables with reference to empirical procedures; instrumentalism treats unobservables as a device that interprets phenomena efficiently. The operationalist interpretation of the permanent income hypothesis requires that there is no a priori concept of permanent income in terms of other theoretical constructs. It is defined in terms of empirical models. But as we have seen, Friedman did not claim that his changing concept: three different definitions of the permanent income, are used interchangeably without recognition of intrinsic differences. Those "operational" models for Friedman do not dictate the notions of the permanent income. Theory influences the measurement procedures via zero-correlation assumptions in the permanent income hypothesis, which make the permanent income hypothesis "operational". Moreover, if operationalist status is sustained, there are no discrepancies between 
economically defined and statistically defined concepts, as in the case of transitory income mentioned above. Thus it is better to interpret Friedman's research method in the spirit of instrumentalism rather than operationalism.

\subsection{Measuring Unobservables}

The definition of the permanent income, especially the one in Income from Independent Professional Practice and Mayer's definition one (M1), states a latent variable problem. A latent variable is such a variable that is not by nature measurable but is related to other measurables. For example, Kmenta (1986 p.581) refers to permanent income as a latent variable that is related to measurables such as age, training and so forth. Hence the permanent income hypothesis is transferred to the category of latent variable models in which transitory income is a disturbance term satisfying all the classical econometric assumptions. Permanent income is specified as a function of a set of measured variables; then measured consumption is regressed on permanent income by plugging in the latent variable function and coefficients are estimated. This modelbuilding process implies a causal relation between the latent variable and observed variables. It allows "objective measurement" within the context of the permanent income hypothesis: e.g., Watts (1960) and Bird and Bodkin (1965) use regression models to estimate the effects between consumption and measurable explanatory variables.

Griliches (1974, p.9) argues that for unobservables such as permanent income, the measurability problem is not the issue because they are only thought of as simplifications. That is to say, an unobservable is a cluster of variables that represent relations of those observables. In this sense Griliches defends Friedman's instrumentalist position stated in A Theory of the Consumption Function such that measuring permanent income is of secondary importance, it is 
evaluated by the interpretability of observed properties between measured income and measured consumption.

\section{CONCLUSION}

In conclusion, there are two matching problems, each relates to a different issue of methodological interest. One is to match the theoretical definition with a formally operational definition. That is, we are concerned with building a model as a more concrete representation of theory 2 . We have seen that the theoretical definition itself is not sufficient to generate the properties subject to test. In spite of claiming that income and consumption consist of permanent and transitory components and the proportional hypothesis it is necessary to add the zerocorrelation assumptions to makes the theory operational. Without the zero-correlation assumptions, it is impossible to derive the less-than-one income elasticity. Even the proportional hypothesis is not capable of being justified for the autocorrelation problem would occur.

The other is to match the theoretical definition with the empirical definition. For example, using nominal returns excluding capital gain from liquid assets as nonhuman wealth is an empirical proxy of permanent income while permanent income is defined as discounted wealth. This measurement problem centers on the role that theoretical definitions play in guiding a precise representation by empirical data. In the case of defining income, Hicks found that his

\footnotetext{
${ }^{22}$ Representation is not necessarily formal (e.g., Morgan (1999) and Morgan and Boumans (1999)), but we say this because in economics, models are mostly referred to as formal models and the meaning 'operational' usually takes a mathematical one.
} 
three definitions are not satisfactory for the purpose of income measurement. Their measurability is so doubtful that they are not useful when treated as measuring instruments.

In this sense, Friedman's permanent income hypothesis entails a different instrument from Hicks's. Economic models aim to predict phenomena as Friedman's instrumentalism states, but it is seems more plausible to put it this way: that, practically, economic models attempt to capture one or several specific properties of phenomena. Thus statistical tests function as a type of characteristics test. Moreover, tests are a type of quality test, that is, they merely tell us whether the property under investigation is statistically significant. They do not tell us the magnitude of the property. Models are good tools if they pass the tests, otherwise they break in our hands.

However, different tools also affect the definitions of theoretical constructs. The permanent income hypothesis is fluid and depends on models. As we measure and model permanent income, the changes of definition are obvious. We have argued that the latent variable version is more a direct transformation from the original verbal statement, but the case of using discounted future receipt is taken to be a received view of permanent income. Thus the interpretation of permanent income as human capacity is not very helpful in the empirical realm. As it is shown in A Theory of the Consumption Function, economists did not try to measure permanent income by establishing correlations between human capacities and permanent income for both are unobservable 2 .

Friedman (1963) strengthened this conviction by interpreting permanent income as expected income. But Friedman's permanent income hypothesis was challenged by James Holms from the viewpoint of econometrics. Holms (1970) argued that in the case of time-series analysis the permanent income model (equations 3-6) is not testable unless the distribution function of

\footnotetext{
${ }^{23}$ But it seems plausible to use expectation terms as a cluster to express human capacity variables.
} 
transitory consumption is specified as a first-order Markov process. In this sense Holms takes Friedman's permanent income model as a 'theoretical model' while the error-term-specified model is a 'measurement model' 24 .

Moreover, Holms (1971) argued that the zero-correlation assumption is not consistent with employing the proxy of an exponentially weighted average of past income. If we apply the adaptive expectation model, then the correlation between permanent income and transitory income would be positive, which violates the assumption of zero correlation between two components. Holms thus concluded that:

Friedman assume that [zero correlation between permanent and transitory income], presumably because this is one of the assumptions necessary to make the permanent income model equivalent to the classical statistical model of errors in observations. This equivalent is destroyed, however, if $Y_{p}$ [permanent income] is measurable. It seems plausible that it is precisely the measurability of $Y_{p}$ that gives this theory its attractiveness to so many economists (1971, p.14).

Adopting the adaptive expectations hypothesis suggests that expected income substitutes for permanent income as the variable explaining current consumption behavior. Just as the expected income approach inspires the later consumption studies that apply the rational expectations hypothesis, it also blurs the distinction between the permanent income hypothesis and the life cycle hypothesis, and, worst of all, economists tend to call long-term income the permanent income no matter how and where it appears 25 .

\footnotetext{
${ }^{24}$ See Spanos (1986).

${ }^{25}$ E.g., Branson (1989) states that the permanent income hypothesis and the life cycle hypothesis are equivalent by using adaptive expectation as the proxy. Also see Deaton (1992) for the argument.
} 
Friedman's idea of permanent income hypothesis progressed from a less empirically adequate model to a satisfactory prediction model, and then to a highly formal model. Income from Independent Professional Practice provided an operational income structure by imposing auxiliary statistical assumptions, but it was not empirically measurable. However, models in $A$ Theory of the Consumption Function are operational and are justified by matching the characteristics of data. The time-series model only deals with formal representation and switches the permanent income hypothesis to the relation between consumption and expected income. Nowadays we learn a new tool in macroeconomics, that is, the theory of consumption behavior based on the rational expectations hypothesis, which was firstly explored by Lucas (1976) and formalized by Hall (1978). It inherited the expected-income-as-the-proxy approach but with more appealing format (rational expectations). Thus it is often called the life cycle-permanent income hypothesis and the latent variable approach is no longer representative of the permanent income hypothesis in macroeconomics.

\section{REFERENCES}

[1] Bird, Roger C. and Bodkin, Ronald G. (1965) 'The National Service Life-Insurance Dividend of 1950 and Consumption: A Further Test of the "Strict" Permanent Income Hypothesis', Journal of Political Economy, 73, pp.499-515.

[2] Blaug, Mark (1998) Great Economists since Keynes, Aldershot: Edward Elgar.

[3] Bodkin, Ronald (1960) "Windfall Income and Consumption", in Friend, Irwin and Jones, Robert (eds.), Proceedings of the Conference on Consumption and Saving, Vol. II, Wharton School of Finance and Commerce, University of Pennsylvania, pp.175-87. 
[4] Branson, William H. (1989) Macroeconomic Theory and Policy, 3rd edn., New York: Harper \& Row.

[5] Bridgeman, Percy W. (1928) The Logic of Modern Physics, New York: MacMillan.

[6] Cagan, Philip (1955) ‘The Monetary Dynamics of Hyperinflation’, in Milton Friedman (ed.) Studies in the Quantity Theory of Money, Chicago, University of Chicago Press, pp. 25-117.

[7] Darby, Michael R. (1972) 'The Allocation of transitory Income Among Consumers' Assets, American Economic Review, 62(5), pp.928-41.

[8] Deaton, Angus (1992) Understanding Consumption Oxford: Oxford University Press.

[9] Fisher, Irving (1907) The Rate of Interest, New York: Macmillan.

[10] Friedman, Milton (1953) Essay in Positive Economics, Chicago: Chicago university Press.

[11] -- (1957) 'The Permanent Income Hypothesis: Comment', American Economic Review, 48, pp.990-91.

[12] -- (1960) 'Comments', in Friend, Irwin and Jones, Robert (eds.), Proceedings of the Conference on Consumption and Saving, Vol. II, Wharton School of Finance and Commerce, University of Pennsylvania, pp.191-205.

[13] -- (1963) 'Windfall, the "Horizon" and Related Concepts in the Permanent Income Hypothesis', in Carl F. Christ (ed.) Measurement in Economics, Stanford: Stanford University Press, pp. 3-28.

[14] Friedman, Milton and Kuznets, Simon (1945) Income from Independent Professional Practice, New York: National Bureau of Economic Research, pp. v-xiii; 325-38; 352-64.

[15] Gilbert, Christopher L. (1986) 'Professor Hendry’s Econometric Methodology', Oxford Bulletin of Economics and Statistics, 48(3), pp.283-307. 
[16] Griliches, Zvi. (1974) 'Errors in Variables and Other Unobservables', in Aigner, D.J. and Goldberger, A.S. (eds.), Latent Variables in Socio-Economic Models, North-Holland, pp.133.

[17] Hall, Robert E. (1978) "Stochastic Implications of the Life Cycle-Permanent Income Hypothesis: Theory and Evidence”, Journal of Political Economy, 86(6), pp.971-87.

[18] Hicks, John R. (1946) Value and Capital, 2nd. edn. Oxford: Oxford University Press.

[19] Hirsch, Abraham and De Marchi, Neil (1990), Milton Friedman: Economics in Theory and Practice, New York: Harvester Wheatsheaf.

[20] Holms, James M. (1970) ‘A Direct Test of Friedman’s Permanent Income Theory’, Journal of American Statistical Association, 65, pp.1159-62.

[21] -- (1971) 'A Condition for Independence of Permanent and Transitory Components of a Series', Journal of American Statistical Association, 66, pp.13-5.

[22] Hynes, J. Allan (1998) 'The Emergence of the Neoclassical Consumption Function: The Formative Years, 1940-1952', Journal of History of Economic Thought, pp.25-50.

[23] Keynes, John M. (1936) The general theory of Employment, Interest and Money, London: Macmillan.

[24] Kim, Jinbang, De Marchi, Neil and Morgan, Mary S. (1995) 'Empirical Model Particularities and Belief in the Natural Rate Hypothesis', Journal of Econometrics, 67:1, pages $81-102$.

[25] Klein, Lawrence R. and Liviatan, Nissan (1957) 'The Significance of Income Variability on Saving Behavior", Oxford University, Institute of Economics and Statistics, Bulletin, 19, pp.156-60.

[26] Kmenta, Jan (1986) Elements of Econometrics, 2nd. edn., New York: Macmillian. 
[27] Koyck, L.M. (1954) Distributed Lags and Investment Analysis, Amsterdam: NorthHolland.

[28] Lucas, Robert E. (1976) "Econometric Policy Evaluation: A Critique”, in Lucas (1981), Studies in Business Cycle Theory, Cambridge: MIT Press, pp.104-30.

[29] Mayer, Thomas (1972) Permanent Income, Wealth, and Consumption: A Critique of the Permanent Income Theory, the Life-Cycle Hypothesis and Related Theories, Berkeley: University of California Press.

[30] Morgan, Mary S. (1999) "Models", in Davis, John B., Hands, D Wade and Maki, Uskali (eds.), The Handbook of Economic Methodology, Cheltenham: Edward Elgar, pp.316-21.

[31] Morgan, Mary S. and Boumans, Marcel (1998) 'The Secrets Hidden by TwoDimensionality: Modelling the Economy as a Hydraulic System', Research Memoranda in History and Methodology of Economics, No. 98-2, Faculty of Economics and Econometrics, University of Amsterdam.

[32] Nerlove, Marc (1958a) 'Distributed Lags and Estimation of Long-Run Supply and Demand Elasticities: theoretical Considerations, Journal of Farm Economics, 40:2, pp.301-11.

[33] -- (1958b) Distributed Lags and Demand Analysis (Agriculture Handbook No. 141), Washington: U.S. Government Printing Office.

[34] Reid, Margaret G. (1952) 'Effect of Income Concept upon Expenditure Curves of Farm Families', in Studies in Income and Wealth, 15, New York: National Bureau of Economic Research.

[35] -- (1953) 'Savings by Family Units in Consecutive Periods' in Heller, Walter W., Boddy, Francis M. and Nelson, Carl L. (eds.), Savings in the Modern Economy, University of Minnesota University Press, pp. 218-20. 
[36] Spanos, Aris (1986) Statistical Foundations of Econometric Modelling, Cambridge: Cambridge University Press.

[37] Watts, Harold W. (1960) 'An Objective Permanent Income Concept for the Household', Cowles Foundation Discussion Paper, No. 99. 